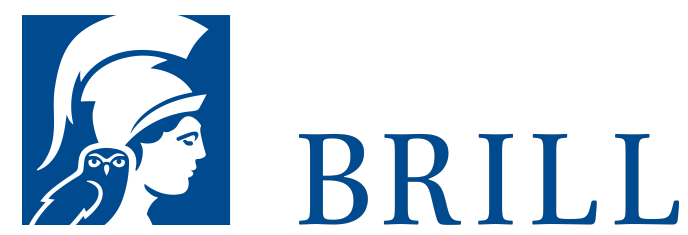

\title{
Montagen des Realen
}

Photographie als Reflexionsmedium und Kulturtechnik

Author: Bernd Stiegler

Begreift man die Photographie als Reflexionsmedium, das in immer wieder neuer und nicht selten $\tilde{A}^{1}$ /4berraschender Weise das auszuloten versucht, was in einer Kultur als RealitÃat verstanden wird, so erÃ ๆffnet sich nicht nur ein neuer Zugang zur Geschichte der Photographie, sondern ergibt sich auch eine Neubestimmung ihrer kulturellen Funktion. Photographien erweisen sich in dieser Perspektive als Montagen des Realen. Die Photographie ist zudem mehr als nur ein technisches Medium unter anderen: sie ist ein Leitmedium des RealitÃatsverstÃøndnisses in hÃ $\llbracket$ chst unterschiedlichen kulturellen Kontexten.

Mit dieser theoretischen Neubestimmung der Photographie geht die Aufgabe einher, das Lesen von Photographien als neue Kulturtechnik in den Blick zu nehmen. Wenn bereits MoholyNagy davon spricht, dass der Analphabet der Zukunft derjenige sein wird, der nicht imstande ist, Photographien zu lesen, so unterstreicht er diese Bedeutung der Photographie als regelrechte neue Kulturtechnik.

$\hat{A} »$ Montagen des RealenÂ« versucht an unterschiedlichen Beispielen, die von der Mitte des 19. Jahrhunderts bis zur Gegenwart reichen und wichtige theoretische Positionen (u.a. Barthes, Sontag, Foucault) ebenso einschlieÃŸen wie paradigmatische Photographen (etwa Chaldej, Rosenthal, Rodchenko und Gursky), die Photographiegeschichte als Kulturtechnik und Reflexionsmedium zu lesen. Dabei kommen literarische...

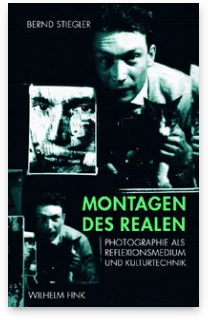

Pages: 331

Seiten, $170 \mathrm{~s} / \mathrm{w}$

Abb.

Language:

German

Subjects:

General, Media

Studies

Publisher: Brill |

Fink

E-Book (PDF)

Released online:

o7 Oct 2019

ISBN: $978-3-$

8467-4795-7

List price

USD A $\$$ A63.00

Paperback

Publication date:

20 May 2009

ISBN: 978-3-

7705-4795-1

List price

USD Â $\$ 63.00$ 
For more information see brill.com

Order information: Order online at brill.com +44330 333 0049 | customerservices@brill.com Submission information: brill.com/authors

Titles published by Brill | Fink, Brill | mentis or Brill | Schöningh: +49(o)715413279216| brill@brocom.de 